\title{
A Study of Nutritional Status and Obesity among the Adult Nepalese of Karseong, Darjeeling District, West Bengal, India
}

\author{
Priyanka Pal, Jyoti Ratan Ghosh \\ Department Anthropology, Visva-Bharati University, Shantiniketan, West Bengal, India \\ Email: priyankapal.0295@gmail.com
}

How to cite this paper: Pal, P., \& Ghosh, J. R. (2022). A Study of Nutritional Status and Obesity among the Adult Nepalese of Karseong, Darjeeling District, West Bengal, India. Advances in Anthropology, 12, 18-28. https://doi.org/10.4236/aa.2022.121003

Received: December 27, 2021

Accepted: February 25, 2022

Published: February 28, 2022

Copyright $\odot 2022$ by author(s) and Scientific Research Publishing Inc. This work is licensed under the Creative Commons Attribution International License (CC BY 4.0).

http://creativecommons.org/licenses/by/4.0/

\begin{abstract}
Obesity is one of the most challenging chronic disease threats facing our country today. It has profound health and economic consequences for our patients and our country. In clinical practice, overweight and obesity are diagnosed by body mass index (BMI), which represents a measure of a patient's weight for their height. There are various reasons why people became fatty and gain overweight. It is a medical problem associated with environmental and socio-economic factors. In some factors, people seem to under nourish and in some conditions people became obese. In this paper, I find out some causes which affect our body, especially daily lifestyle. I need to take some anthropometric measurements to check their nutritional status and I did some statistical analysis to experiment with the interrelationship between BMI (body mass index) and anthropometry. Which one is better to calculate obesity, BMI or Anthropometry was my aim to find out. I did my experiment on the population of the hilly area. I did work among 106 individuals cross-sectionally. As result, I got a strong relationship between BMI and anthropometry. After all, this study proves WC indicates better fat distribution.
\end{abstract}

\section{Keywords}

Obesity, Chronic Disease, BMI, Anthropometry, Socio-Economy, Relationship, Statistics, under Nourish, Fat Distribution

\section{Introduction}

Over the past two decades, the Asia and Pacific region saw a rapid increase in overweight people and obesity. The latest available data indicated that over 
$40.9 \%$ of adults in the region are overweight compared to $34.6 \%$ in 1990 . It is well documented that obesity and overweight are one of the main risk factors of non-communicable diseases. Non-communicable diseases have various causes. The World Health Organization (WHO) identifies four modifiable risk factors of behaviours-tobacco use, physical inactivity, unhealthy diet, and the harmful use of alcohol (WHO, 2017). The second and third of these risk factors typically find their expression in overweight and obesity. Overweight is commonly defined as a body mass index (BMI) exceeding 25, while obesity starts when the BMI surpasses 30 (WHO, 2016). Today, Asia and the Pacific region are home to the largest absolute number of overweight and obese people, equivalent to about 1 billion. In the Asia and Pacific region, two out of every five adults in the region are either overweight or obese (Helble \& Francisco, 2014).

Obesity has reached epidemic proportions in the world today. The World Health Organization (WHO) has estimated that worldwide obesity has more than doubled from 1980 to 2008. It is thought that more than 1.4 billion adults, aged 20 years and older, are overweight and up to one quarter of them obese. 3 Overweight and obesity are leading risks for global deaths. It is estimated that at least 2.8 million. Adults die each year as a result of being overweight or obese. 3 The strong association of obesity with diabetes mellitus and ischemic heart disease is well known, but increasingly its association with cancers has also been recognized (Goh \& Goh, 2013).

The battle against obesity has become one of the greatest public health challenges of the twenty-first century. Prevalence of obesity in the Asia-Pacific regions of the world has typically been lower than that in Europe or the United States. However, increases in urbanization and westernization of many developing countries are now resulting in increased prevalence of over-weight and obesity with trends towards more sedentary lifestyles and energy-dense diets with increased fat content. Overweight and obesity are major contributing factors for cardiovascular diseases in America, the first and second leading cause of death among Asian American and Pacific Islander men and women, respectively. It is found that the increase in obesity in the Asia Pacific region has tended to exhibit a higher risk for metabolic diseases at lower Body Mass Index (BMI) than to Europeans as well as higher body fat percentages at the same age, sex, and BMI. For these reasons, World Health Organization and Obesity Task Force suggest lower BMI standers are normal (18.6 - 24.9), overweight (25 - 29.9), and obese $(>30)$. The lower cut-off points for those of Asian Pacific descent are normal (18.6 - 22.9), overweight (23 - 27.4), and obese (>27.5). The lowered cut-off points were found clinically relevant among many populations in Asia, including Taiwanese, Korean, Japanese, Chinese, Malays, and Asian Indians (Ng, 2009).

Although Asian countries have some of the lowest prevalence of overweight and obesity worldwide, they are experiencing alarming rates of increase in recent years. Vietnam and India have the lowest rates of obesity in Asia Pacific $1.7 \%$ and $1.9 \%$ respectively). Malaysia has the highest obesity prevalence at $14 \%$ in the South East Asia region, with Thailand next in line (8.8\%). These figures fall far 
behind those in the Oceanic countries, with $26.8 \%$ obesity rates in Australia and $28.3 \%$ in New Zealand. The prevalence of obesity in these countries is similar to rates seen in the United Kingdom (26.9\%) and US (33\%). As of today, effective drugs for weight loss have yet to surface. As such, public health initiatives are considered one of the most important elements of obesity control and prevention. Although some progress has been made to curb overweight and obesity, much of Asia is still unaware of the consequences of obesity. In contrast to the West, where the consumption of fast food is considered cheap and time-saving. With economic development and easier access to fast food, households are able to indulge in energy-dense foods, along with luxury entertainments that encourage sedentary lifestyles. In China parents and grandparents are constantly worried that their child/grandchild is not eating enough. A recent study revealed that $72 \%$ of Chinese mothers thought their overweight children were normal or underweight. 15 Thus, altering the cultural perception that "fat is prosperity" is essential for curbing the rise in overweight and obesity. We currently see that Asia is a divergence in nutritional status across geographical regions and socioeconomic status. This makes it difficult to generalize how increasing overweight and obesity rates will impact the Asian market. If the average BMI of the population increases, the additional mortality and morbidity risks may already be reflected in the baseline pricing (Cheong, 2014).

Today, Asia and the Pacific region are home to the largest absolute number of overweight and obese people, equivalent to about 1 billion. In the Asia and Pacific region, two out of every five adults in the region are either overweight or obese. Public health experts are increasingly aware of the main determinants of the fast propagation in the region. Economic growth made food increasingly available at lower prices. While it helped to lower the incidence of stunting and wasting, it also increased the possibilities of overeating and excessive weight gain. One engine of growth in the region has been the shift from agriculture to manufacturing industries and more recently to services. Jobs in manufacturing and services typically require less physical activity and can lead to overweight. The rapid urbanization of Asia has been another contributing factor to the increase in overweight. Asia saw its urban population increase from about one third in 1990 to one half in 2015. Urbanization typically means a more sedentary lifestyle, at work and at home (Helble \& Francisco, 2014).

\section{Objectives}

My objectives of this study were to measure obesity and consciousness about obesity among the karseong people. I tried to find out the inter-relationship between BMI and anthropometric measurements. And my focus was on their nutrition and daily lifestyle. These two areas of study are very important for understanding the cause of being obese (Omer, 2020).

\section{Literature Review}

According to the World Health Organisation WHO (2016), there are just under 
2 billion overweight adults in the world. More than 600 million of them are considered obese. Around 40\% of adults were overweight in 2016 and just under $15 \%$ were obese. The global prevalence of obesity has increased threefold between 1975 and 2016. If the trend continues to rise, it is estimated that close to one third of the world adult population will be overweight and more than 1 billion will be obese by 2025 .

Obesity is a medical condition in which excess body fat has accumulated to the extent that it may have a negative effect on health. People are generally considered obese when their Body Mass Index (BMI) is over $30 \mathrm{~kg}$ as WHO's commitment. BMI is measured by an individual's weight divided by height $\left(\mathrm{m}^{2}\right)$. The range $25-30 \mathrm{~kg} / \mathrm{m}^{2}$ is defined as over-weight (Jaiswal et al., 2017).

In male only BMI and WHR have no correlation where other parameters, BMI have a correlation with MUAC, WC and WHR with WC. Similarly, WC and BMI are correlated is found in Nigeria, there 400 people are chosen where the researcher confirmed that obese men, WC is a better predictor of the distribution of adipose tissue among several fat components in the abdominal region than WHR index (Odenigbo et al., 2011).

A study of (200 urban women) in Odisha, India was seen that 50 percent of women are pre obese and 28.4 percent of women are obese, while calculating the WHR 69 percent of women are normal and only 31 percent of women are under obese categories. BMI has also a significant correlation with WHR, MUAC and waist circumference, WHR has a significant correlation with weight, MUAC and waist circumference (Kar, 2016).

In another research, $56.4 \%$ of females are at risk at the basis of WHR $>0.85$ is similar to this study. The mean of BMI is $19.59 \pm 3.56 \mathrm{~kg} / \mathrm{m}^{2}$ and the prevalence of obesity were 7.6\% (Amarathunga et al., 2017).

Another researcher confirmed that obese people reported a higher average time of TV watching (Mean \pm SD: $3.6 \pm 1.5 \mathrm{~h}$ /day) than non-obese ones $(3.0 \pm$ $1.4 \mathrm{~h} /$ day). People in the highest category of TV watching $\geq 4 /$ day a high POR (prevalence rate ratio) obesity than those in the lowest category $\leq 1 \mathrm{~h}$ /day (Vioque et al., 2000).

\section{Methods}

Participants-One hundred of six adults were selected from the age group between 18 to 80 years in Karseong, District-Darjeeling and their obesity were measured by their socio-cultural condition, while their educational status, economical condition was followed. The ecology of that area has also been followed because the subject of ecology affects obesity. The cross-sectional longitude study was done among 106 individuals including 57 females and 49 males. The economic standard was taken to associate their nutrition and the literacy rate considered for health consciousness. They are basically service person and some are working as labourer or own business. The women are maximum dependable, few women were worker. 


\subsection{Anthropometric Measurement}

Standing height was measured to the nearest centimetres $(\mathrm{cm})$ using by anthropometer with the subject standing erect on a horizontal resting plane, bare footed and with the palms of the hands facing forward and the fingers pointing downwards. The height was measured keeping each subject's head in the Frankfurt plane. The measurements were taken from the sole of the feet to the vertex of the head (Jaiswal et al., 2017).

The weight of individuals is measured by a standard weighing machine. The measurement was taken before meal and shoe off an individual with light cloth. The measurement was kept from zero pointer. BMI was calculated by dividing weight (kg) by converted height (M2) (Jaiswal et al., 2017).

The MUAC was measured to the nearest centimetre using a calibrated nonstretch tape with the left arm hanging relaxed and was taken midway between the tip of acromion and olecranon process. MUAC was measured with the child wearing light clothing and the sleeves rolled up (Jaiswal et al., 2017).

Waist circumference was measured at the level midway between the lower rib margin and the iliac crest with participants in standing position without heavy outer garments and with emptied pockets, breathing out gently (Jaiswal et al., 2017).

Hip circumference was recorded as the maximum circumference over the buttocks. WHR was consequently calculated as the ratio of waist circumference over the hip circumference (Jaiswal et al., 2017).

\subsection{Statistical}

The data are analyzed by Microsoft office Excel 2007. Mean and SD were calculated of each data with age and sex. Differences between boys and girls were determined using unpaired t-tests for continuous variables. The participants were divided into sex-specific (male and female) and follow the WHO guidelines.

Statistical analysis: Data is analyzed by the windows MS Excel 2007. Mean, Standard deviation are done of all categories of variables. T test is done to comparison of the Height, Weight, WC, HC, MUAC between male and female. Correlation and regression are done to consider the significance or relation of MUAC BMI, WC and WHR of both male and female individuals.

\section{Results}

In Table 1, the study population was in the age group $18^{\text {th }}$ to 83 years where there have 49 male and 57 female and their mean of age is $44.59 \pm 42.1$, their Height, Weight, WC, HC, MUAC and BMI was $162.74 \pm 151.45$, $59.25 \pm 53.4$, $85.25 \pm 87.82,97.35 \pm 95.81,29.08 \pm 28.48,21.9 \pm 23.52$. Their per month income was $21,714.29 \pm 9214.286$.

The percentage is dependent on total population of 49 males and 57 females.

In the population had seen $46.93 \%$ male were worker among the 49 male individuals, they were engaged many types of job, among them $10.2 \%$ had own 
Table 1. Basic characteristics of studied population.

\begin{tabular}{|c|c|c|}
\hline Variables & Mean & SD \\
\hline \multicolumn{3}{|l|}{ Age (Year) } \\
\hline Male & 44.59 & 10.41 \\
\hline Female & 42.1 & 17.12 \\
\hline \multicolumn{3}{|l|}{ Monthly Income (Rs.) } \\
\hline Male & $21,714.29$ & $73,821.08$ \\
\hline Female & 9214.286 & 7988.831 \\
\hline \multicolumn{3}{|l|}{ Height (cm) } \\
\hline Male & 162.74 & 10.10736 \\
\hline Female & 151.45 & 7.189256 \\
\hline \multicolumn{3}{|l|}{ Weight (Kg) } \\
\hline Male & 59.25 & 10.14489 \\
\hline Female & 53.4 & 11.28504 \\
\hline \multicolumn{3}{|l|}{ MWC (cm) } \\
\hline Male & 85.25 & 15.20177 \\
\hline Female & 87.82 & 13.21859 \\
\hline \multicolumn{3}{|l|}{$\mathrm{MHC}(\mathrm{cm})$} \\
\hline Male & 97.35 & 6.870832 \\
\hline Female & 95.81 & 15.67869 \\
\hline \multicolumn{3}{|l|}{ MUAC (cm) } \\
\hline Male & 29.08 & 5.354965 \\
\hline Female & 28.48 & 3.964431 \\
\hline \multicolumn{3}{|l|}{ BMI } \\
\hline Male & 21.9 & 3.495263 \\
\hline Female & 23.52 & 4.784169 \\
\hline
\end{tabular}

WC-Mid Upper Arm Circumferences, HC-Hip Circumference, WC-Waist Circumference, BMI-Body Mass Index, SD-Standard Deviation.

business, $22.44 \%$ had services, $8.16 \%$ worked as labor, and $6.12 \%$ had other jobs. Among the female individuals, $12.28 \%$ females were workers while $1.75 \%$ had business, $7.01 \%$ had services and 3.5\% had worked as labor. The differences are seen by Table 2 that the females are very less do work they are dependable on their men.

Table 3 shows the prevalence of BMI range among the male $63.26 \%$ and 64.91\%. under the range of BMI 18.5 - 24.9 which is considered Normal. $18.36 \%$ male and $10.52 \%$ female goes to $<18.5$ which is considered under nourished. Among the hundred six population, $18.36 \%$ and $14.28 \%$ go to overweight, BMI range 25.0 - 25.9. And 10.52 percent of females are seen obese.

Table 4 consists the abdominal obesity of males and females where seen that $53.06 \%$ males and $43.58 \%$ females are under WHR range of $<0.85$ while $46.93 \%$ male and $56.94 \%$ female are obese. 
Table 2. Occupational status of studied population.

\begin{tabular}{ccccc}
\hline Variables & Male & Percentage (\%) & Female & Percentage (\%) \\
\hline Business & 5 & 10.2 & 1 & 1.75 \\
Service & 11 & 22.44 & 4 & 7.01 \\
Labor & 4 & 8.16 & 2 & 3.5 \\
Other & 3 & 6.12 & 0 & 0 \\
Total & 23 & 46.93 & 7 & 12.28 \\
\hline
\end{tabular}

Table 3. Prevalence of BMI of studied population.

\begin{tabular}{cccccc}
\hline CATEGORY & Male & percentage & Female & Percentage & BMI Range \\
\hline Normal & 31 & 63.26 & 37 & 64.91 & $18.5-24.9$ \\
Under Nourished & 9 & 18.36 & 6 & 10.52 & $<18.5$ \\
Over Weight & 9 & 18.36 & 7 & 14.28 & $25.0-25.9$ \\
Obese & 0 & 0 & 7 & 10.52 & $30.0-34.9$ \\
\hline
\end{tabular}

Table 4. Prevalence of abdominal obesity of studied population.

\begin{tabular}{cccccc}
\hline Category & Male & Percentage & Female & Percentage & WHR range \\
\hline Normal & 26 & 53.06 & 25 & 43.58 & $<0.85$ \\
Obese & 23 & 46.93 & 32 & 56.14 & $>0.85$ \\
\hline
\end{tabular}

In Table 5, the descriptive characteristics are shown that overall male-female are significantly different in mean weight, height, WC, HC, MUAC and BMI.

Table 6 shows a significantly strong correlation BMI with MUAC, WC and between WHR and WC $(\mathrm{p}<0.05)$ but BMI and WHR are significantly not correlated $(\mathrm{p}>0.05)$.

Table 7 demonstrated a strong correlation among the screening tool of female BMI vs MUAC, WC, WHR and WHR vs WC $(\mathrm{p}<0.05)$.

Table 8 of behavioral characteristics of participants show that the life style of studied population while their sleeping time, alcohol drinking, smoking habits, they do any physical activities or not, awareness of obesity.

Table 9 demonstrates the obesity depending on smoking habit and watching TV on leisure time. Here seen that 18.36 percent of males have obesity among the 21.69 percent of males who were smoked. 6.12 percent of males have overweight or pre-obese who were not smoked and 4.08 percent of males have overweight who was smoke daily. On the other side, 14.28 percent has obese but they are not smoked.

\section{Discussion}

In the population women were seen as unemployed and dependable, they are maximum housewives. They were busy in their house work like child bearers and reared, they did have not enough time for recreational or sporting activities but 
Table 5. Descriptive characteristics of studied population.

\begin{tabular}{ccccccc}
\hline Variance & $\begin{array}{c}\text { Height } \\
(\mathrm{cm}) \\
\text { Mean (SD) }\end{array}$ & $\begin{array}{c}\text { Weight } \\
(\mathrm{Kg})\end{array}$ & $\begin{array}{c}\text { WC }(\mathrm{cm}) \\
\text { Mean (SD) }\end{array}$ & $\begin{array}{c}\text { HC (cm) } \\
\text { Mean (SD) }\end{array}$ & $\begin{array}{c}\text { MUAC } \\
(\mathrm{cm}) \\
\text { Mean } \\
(\mathrm{SD})\end{array}$ & $\begin{array}{c}\text { BMI } \\
\left(\mathrm{kg} / \mathrm{m}^{2}\right) \\
\text { Mean } \\
(\mathrm{SD})\end{array}$ \\
\hline Male & 162.58 & 59.31 & 86.85 & 97.38 & 29.78 & 22.47 \\
& $(10.10)$ & $(10.14)$ & $(15.20)$ & $(6.87)$ & $(5.35)$ & $(3.50)$ \\
Female & 151.42 & 53.48 & 87.88 & 95.78 & 28.50 & 23.56 \\
& $(1.18)$ & $(11.28)$ & $(13.21)$ & $(15.67)$ & $(3.96)$ & $(4.78)$ \\
t test & 6.53 & 2.8 & -0.89 & 0.64 & 1.34 & -1.38 \\
p-value & $\mathrm{p}>0.05$ & $\mathrm{p}>0.05$ & $\mathrm{p}>0.05$ & $\mathrm{p}>0.05$ & $\mathrm{p}>0.05$ & $\mathrm{p}>0.05$ \\
\hline
\end{tabular}

Table 6. Correlation coefficient of BMI with anthropometric parameters of male in studied population.

\begin{tabular}{ccc}
\hline Male & Correlation coefficient $(\mathrm{r})$ & P value \\
\hline BMI vs MUAC & 0.46 & $\mathrm{p}<0.05$ \\
BMI vs WHR & 0.32 & $\mathrm{p}>0.05$ \\
BMI vs WC & 0.56 & $\mathrm{p}<0.05$ \\
WHR vs WC & 0.92 & $\mathrm{p}<0.05$ \\
\hline
\end{tabular}

Table 7. Correlation between the diagnostic parameter of female.

\begin{tabular}{ccc}
\hline Female & Correlation coefficient $(\mathrm{r})$ & P value \\
\hline BMI vs MUAC & 0.61 & $\mathrm{p}<0.05$ \\
BMI vs WC & 0.73 & $\mathrm{p}<0.05$ \\
BMI vs WHR & 0.36 & $\mathrm{p}<0.05$ \\
WHR vs WC & 0.92 & $\mathrm{p}<0.05$ \\
\hline
\end{tabular}

some of them try to do for health. There are seen that people are passed their leisure time by watching TV and the analysis show that 4 hour/day daily watching TV indicate the risk of obesity among women (Table 2).

In this study, 10.52 percent of women were found obese where men have no obesity and 18.36 percent of men are seen under nourished than women. Their weight, WC, BMI and MUAC have seen the mean differences. The waist circumferences are seen positive relation with BMI, MUAC and WHR but in male WC have seen negative relation. This correlation study proved that the WC indicated better fat distribution in abdominal region than WHR index (Table 3).

In the observational season it was seen that they had abdominal obesity and the distribution of male and female is not so far (Table 4). If describe the obesity through waist hip ratio (WHR) then it would see that they had more obesity rate. But it is only abdominal fat that indicates obesity.

This study also says that the weight, MUAC and BMI have no significance 
Table 8. Behavioral characteristics.

\begin{tabular}{|c|c|c|}
\hline Sleeping time & Male & Female \\
\hline$>8$ & 13 & 20 \\
\hline Percentage (\%) & 12.26 & 18.86 \\
\hline$<8$ & 11 & 15 \\
\hline Percentage (\%) & 10.37 & 14.15 \\
\hline 8 & 25 & 22 \\
\hline Percentage (\%) & 23.58 & 20.75 \\
\hline \multicolumn{3}{|l|}{ Alcohol Drinking } \\
\hline Yes & 27 & 0 \\
\hline Percentage (\%) & 25.47 & 0 \\
\hline No & 9 & 57 \\
\hline Percentage (\%) & 8.49 & 100 \\
\hline Daily & 17 & \\
\hline Percentage (\%) & 34.69 & \\
\hline Occasionally & 10 & \\
\hline Percentage (\%) & 9.43 & \\
\hline \multicolumn{3}{|l|}{ Smoking Habits } \\
\hline Yes & 23 & 1 \\
\hline Percentage (\%) & 21.69 & 0.94 \\
\hline No & 29 & 56 \\
\hline Percentage (\%) & 27.35 & 52.83 \\
\hline Daily & 16 & \\
\hline Percentage (\%) & 32.65 & \\
\hline Occasionally & 7 & \\
\hline Percentage (\%) & 14.28 & \\
\hline \multicolumn{3}{|l|}{ Did you do any physical activity } \\
\hline Yes & 3 & 2 \\
\hline Percentage (\%) & 2.8 & 1.8 \\
\hline No & 46 & 55 \\
\hline Percentage (\%) & 43.39 & 51.88 \\
\hline \multicolumn{3}{|l|}{ Awareness of obesity } \\
\hline Yes & 15 & 20 \\
\hline Percentage (\%) & 14.15 & 18.86 \\
\hline No & 34 & 37 \\
\hline Percentage (\%) & 32.07 & 34.9 \\
\hline
\end{tabular}


Table 9. Prevalence of obesity depending on smoking habit and watching TV of studied population.

\begin{tabular}{lcccc}
\hline Smoking Habits & Male & Overweight & Female & Obese \\
\hline Yes & 23 & 9 & 1 & 0 \\
Percentage (\%) & 21.69 & 18.36 & 0.94 & 0 \\
No & 29 & 3 & 56 & 7 \\
Percentage (\%) & 27.35 & 6.12 & 52.83 & 14.28 \\
Daily & 16 & 2 & & \\
Percentage (\%) & 32.65 & 4.08 & & \\
Occasionally & 7 & 0 & & \\
Percentage (\%) & 14.28 & 0 & & \\
Watching TV & & & & 1.75 \\
1 h & 32 & 3 & 19.29 & 2 \\
Percentage (\%) & 65.3 & 6.12 & 13 & 3.5 \\
2 h & 15 & 5 & 22.8 & 4.01 \\
Percentage (\%) & 30.61 & 10.2 & 33 & \\
4 h & 2 & 1 & 57.89 & \\
Percentage (\%) & 4.08 & 2.04 & & \\
\hline
\end{tabular}

between male and female where height, WC and HC differ a high significance (Table 5).

The correlation among the parameter of male and female is considered that WC is more effectible in obese than other indexes and MUAC also predict the fat distribution (Table 6 and Table 7).

In the following study, it can see that there had a lack of health consciousness among them. They live in random, daily smoking and drinking habits though the percentage is low they are not aware of obesity (Table 8).

It is seen in this study that the population of Karseong females had obesity rather than male. Even the men's goes to latent obese or overweight but not call obesity. Only $18.36 \%$ of male are going on overweight and $10.52 \%$ of women were obsessed (Table 9).

\section{Conclusion}

In this study, we can see that women are obsessed and the main cause of their obesity is that they are housewives. They do their work at home and in their free time, they watch tv or do other work by sitting, some of consuming medicine because they have some chronic diseases which affect their health. On the other hand, the men are very busy in their work, they giving hard labour, for this reason sometimes their health fall. Some of them have seen undernourished conditions. The statistic says that the waist circumference is indicate better fat distribution than WHR index in abdominal region. 


\section{Conflicts of Interest}

The authors declare no conflicts of interest regarding the publication of this paper.

\section{References}

Amarathunga, D., Samarakoon, N. A., \& Perera, P. P. R. (2017). Prevalence of Obesity, Central Obesity and Relationship between Body Mass Index, Selected Anthropometric Parameters and Body Fat Percentage in a Sri Lankan Female Population. Imperial Journal of Interdisciplinary Research, 3.

Cheong, W. S. (2014, December). Overweight and Obesity in Asia, Singapore (Vol. 40). General Reinsurance AG.

Goh, L. Y., \& Goh, K. L. (April, 2013). Obesity: An Epidemiological Perspective from Asia and Its Relationship to Gastrointestinal and Liver Cancers. The Journal of Clinical Endocrinology \& Metabolism, 98, $28 \mathrm{p}$.

Helble, M., \& Francisco, K. (December, 2017). Overweight and Obesity. In Asia ADBI Working Paper Series. Asian Development Bank Institute.

Jaiswal, M., Bansal, R., \& Agarwal, A. (2017, August). Role of Mid-Upper Arm Circumference for Determining Overweight and Obesity in Children and Adolescents. Journal of Clinical and Diagnostic Research, 11, SC05-SC08. https://doi.org/10.7860/JCDR/2017/27442.10422

Kar, D. (June, 2016). Body Mass Index, Waist Hip Ratio and It's Correlation among Urban Women of Sambalpur City in Odisha. Asian Journal of Home Science, 11, 142-150. https://doi.org/10.15740/HAS/AJHS/11.1/142-150

Ng, T., McMahan, S., Mouttapa, M., Tanjaisri, S. P., \& Beam, W. (2009). Comparison of Body Mass Index (BMI) Categories Based on Asian and Universal Standards and Language Spoken at Home among Asian American University Students. American Journal of Health Education, 40, 37-44. https://doi.org/10.1080/19325037.2009.10599077

Odenigbo, U. M., Odenigbo, U. C., Odenigbo, O. C. \& Adogu, P. O. U. (2011). Relation of Waist Circumferences, Waist Hip Ratio and Body Mass Index as Predictors of Obesity in Adult Nigerian. Pakistan Journal of Nutrition, 10, 15-18. https://doi.org/10.3923/pjn.2011.15.18

Omer, T. (March, 2020). The Causes of Obesity: An In-Depth Review. Advances in Obesity, Weight Management \& Control, 10, 90-94. https://doi.org/10.15406/aowmc.2020.10.00312

Vioque, J., Torres, A., \& Quiles, J. (2000). Time Spent Watching Television, Sleep Duration and Obesity in Adults Living in Valencia, Spain. International Journal of Obesity, 24, 1683-1688. https://doi.org/10.1038/sj.ijo.0801434

World Health Organization (WHO) (2016) Health Topic-Overweight and Obesity. WHO. World Health Organization (WHO) (2017) Health Topic-Overweight and Obesity. WHO. 